\title{
/COMMENTARY
}

\section{Gene Flow and Bacterial Transformation}

\author{
B ER NARD DIXON
}

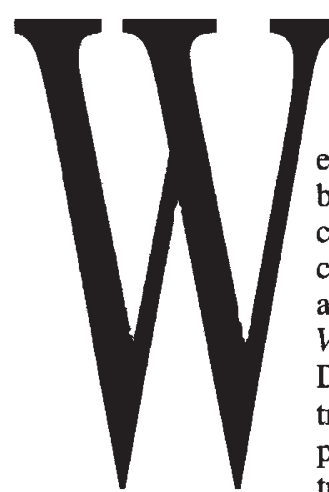

e all know that plasmids can be transferred when bacteria come together in the act of conjugation. But were you aware that marine strains of Vibrio also take up plasmid DNA by a similar process of transformation-and that this probably occurs naturally in tropical and subtropical areas?

We all know that salmonellae, "removed" during sewage disposal, can persist in the waste sludge that is then sprayed on agricultural land as fertilizer. But were you aware that salmonellae in the soil may become nonculturable, and thus nondetectable by conventional methods, while remaining viable?

I ask these questions because of continuing concern over an issue covered in this column about two years ago(Bio/Technology 9:403, 1991). At that time, Tyler Kokjohn and others had just established that bacteriophages were important effectors of microbial ecology in aquatic ecosystems. Coupled with the relatively recent disclosure that the load of phages in natural waters was three to seven orders of magnitude higher than previously supposed, this prompted a query. Was our knowledge of lateral gene flow as secure as may scientists supposed? I emphasized that I was not opposed in principle to the release of genetically modified organisms, and that these discoveries did not indicate any concrete hazard. They simply gave pause for thought.

Two papers, one on Vibrio and the other on salmonellae, now bring us back to these same issues. The first is by Marc Frischer and coworkers at the University of South Florida. Published in the current issue of the Journal of General Microbiology (139: $753,1993)$, it extends yet again our knowledge of DNA movements among bacteria.

Until recently the transfer of genetic information between prokaryotes was thought to take place solely through transformation, conjugation, and transduction. In the past few years, however, evidence has emerged that plasmids, normally ferried through the pilli and bridges of sexual conjugation, can pass directly into bacterial cells by transformation. Most research into transformation has focused on genera of medical importance, especially hemophilus and streptococcus. But what role does this newly discovered process play in the dissemination of DNA among nonpathogens in the environment?

A couple of years ago Frischer and his colleagues described several marine Vibrio strains with high frequencies of transformation in laboratory glass- ware, which can certainly be transformed by plasmid DNA. Last year they reported that one of their isolates was capable of intergeneric transformation with Escherichia coli. In an effort to learn whether this type of process takes place in the biosphere, they have now grown one of these organisms in artificial sea water and measured the effects of salinity, temperature, and nutrients.

Exposed to DNA at levels known to occur in marine environments, the cells transformed extremely efficiently in water, whether it was enriched or nutrientfree, and maintained this capacity for at least 10 days. Temperatures from 4 to 33 degrees Celsius had no significant effect on the rate of transformation, nor did salinities between 12 and 50 parts per thousand. Transformation was impaired only under extreme temperatures and salinities that occur very rarely in estuarine environments. The authors concluded that as their Vibrio is transformed by plasmids under such a wide range of conditions, this type of gene transfer probably does take place in tropical and subtropical estuaries. Moreover, the persistence of transformation even under starvation conditions suggests that it happens in nature in organisms that are physiologically dormant.

So to our second paper, a report by researchers at the University of Warwick (P.E. Turpin et al., Journal of Applied Bacteriology 74:421, 1993). Concerned about health hazards posed by sewage sludge sprayed over arable land, they have been monitoring the survival of salmonella in the soil. Over the past decade, several studies have shown that at least some bacteria, exposed to stress in the laboratory or the environment, pass into a dormant state in which they remain viable but do not show up on agar plates. Until now no one has investigated the possibility of salmonellae in the soil becoming noncultural yet retaining viability.

The Warwick team has developed two techniques (an ELISA and a fluorescent antibody direct count) to evaluate the survival of $S$. typhimurium in soil, and used them to establish that the organisms do indeed go into the dormant condition. Conventional plate counts fell rapidly with time when salmonellae were added to soil in a microcosm, whereas counts using the two new methods remained high.

As two years ago, none of this indicates a specific, identifiable hazard to be considered when assessing a possible genetically modified organism release. Nevertheless, these papers do demonstrate that there have been two highly significant lacunae - in our knowledge of natural gene flow, and in our ability to monitor organisms in the environment. 